\title{
Assessment of health-related quality of life in patients with multiple sclerosis living in the Fars province of Iran
}

\author{
Nahid Ashjazadeh ${ }^{1}$, Habib Hadianfard², Soodabe Feridoni ${ }^{2,3}$, Elham Farjam² \\ ${ }^{1}$ Department of Neurology, Shiraz Neuroscience Research Center, Shiraz University of Medical Sciences, Shiraz 7194815644, Iran. \\ ${ }^{2}$ Department of Clinical Psychology, Shiraz University, Shiraz 7194815644, Iran. \\ ${ }^{3}$ Department of Neurology, Clinical Neurology Research Center, Shiraz University of Medical Sciences, Shiraz 7194815644, Iran.
}

\section{A B S T R A C T}

Aim: The aim of this study is to determine the health-related quality of life (HRQoL) among patients with multiple sclerosis (MS) living in the Fars province of Iran. Methods: A total of 100 patients with clinically definite MS who were referred to a clinic affiliated with Shiraz University of Medical Sciences were eligible to participate in this study. The HRQoL was evaluated using a Persian version of the Medical Outcomes software. Data were analyzed using descriptive statistics, MANOVA, ANOVA and an independent $t$-test. Results: Patient variables in this sample included the following: $80 \%$ of the participants were female, $68 \%$ of the participants were married, $30 \%$ of the participants had completed primary school, $38 \%$ of the participants had completed high school and $32 \%$ of the participants attained a university degree. No significant difference among $\mathrm{HRQ}$ oL scores attributable to these variables were observed among participants in this study. The overall mean scores for the physical and mental components of the HRQoL were $59.48 \pm 24.63$ and $49.26 \pm 23.15$, respectively. The paired $t$-test showed that when compared with a normal sample, the patients in this study had mental component scores of the HRQoL that were significantly lower than physical component scores $(t=5.72, \mathrm{df}=99, P<0.001)$. Conclusion: The HRQoL scores among patients with MS are significantly lower than those among members of the healthy population, especially with respect to the mental component of the test. Therefore, close consideration of mental and physical problems and appropriate management of MS can improve quality of life in these patients.

Key words: Health-related quality of life; multiple sclerosis; medical outcomes software

\section{INTRODUCTION}

Multiple sclerosis(MS) is a progressive diseaseaffecting the central nervous system that causes immunemediated damage to the myelin sheath, which results in physical and cognitive impairments. Multiple sclerosis is a complex disease with different signs and symptoms. These signs and symptoms depend on the extent and location of the nerve damage. The disease pattern is mixed and punctuated by periodic attacks with partial recovery exhibited between the attacks. ${ }^{[1]}$ The Multiple Sclerosis International Federation Report suggests that the number of patients with MS has increased from 30 to 33 per 100,000 between 2008 and 2013 with the prevalence of the disease among

Corresponding Author: Dr. Habib Hadianfard, Department of Clinical Psychology, Shiraz University of Medical Sciences, Shiraz 7194815644, Fars, Iran. E-mail: hadianfardh@gmail.com

\begin{tabular}{|l|l|}
\hline \multicolumn{2}{|c|}{ Access this article online } \\
\hline Quick Response Code: & Website: \\
\hline & www.nnjournal.net \\
\hline
\end{tabular}

women twice that of men. ${ }^{[2]}$

MS is a chronic progressive disease without cure that begins during early adulthood. Patients with MS live with this disease for a long period of time, and it negatively influences their social, economic and emotional well-being. ${ }^{[2]}$ Health-related quality of life (HRQoL) is a multidimensional concept that includes physical, social, and emotional aspects of life and is an essential indicator to evaluate the impact of therapeutic plans on the lives of patients with MS. ${ }^{[3]}$ Earlier research has also documented the impact of gender differences and education level on HRQoL scores. ${ }^{[4,5]}$ This previous research has suggested that there is a significant positive correlation between

This is an open access article distributed under the terms of the Creative Commons Attribution-NonCommercial-ShareAlike 3.0 License, which allows others to remix, tweak, and build upon the work non-commercially, as long as the author is credited and the new creations are licensed under the identical terms.

For reprints contact: service@oaepublish.com

Cite this article as: Ashjazadeh $\mathrm{N}$, Hadianfard $\mathrm{H}$, Feridoni S, Farjam E. Assessment of health-related quality of life in patients with multiple sclerosis living in the Fars province of Iran. Neuroimmunol Neuroinflammation 2016;3:57-62.

Received: 29-09-2015; Accepted: 18-12-2015 
demographic factors, such as marital status, level of education and employment status, with HRQoL in patients with chronic diseases. ${ }^{[6,7]}$ For example, employed patients have reported better emotional wellbeing and married patients have reported better sexual function than that of patients who were unemployed or unmarried, respectively. ${ }^{[6]}$

HRQoL measures a patient's level of satisfaction with life.$^{[3]}$ Knowing patient outcomes and level of satisfaction is essential for the success of treatments provided by a health-care provider. The aim of this descriptivecomparative study is to assess the HRQoL in patients with MS.

\section{METHODS}

A total of 100 patients with MS, aged between 16 and 65 years, were selected for participation in this study. The 2010 revision of the McDonald criteria $^{[8]}$ was used to confirm a diagnosis of MS. The participants were selected from a pool of all MS outpatients who were referred to the medical clinics at Shiraz University of Medical Sciences during 2012 using the convenient non-probability sampling method. Patients who received high doses of methylprednisolone administered as pulse therapy during the past 3 months as well as patients with chronic co-morbid diseases such as cancer, diabetes, epilepsy, renal failure, and heart disease, or major psychological problems, such as psychosis, were excluded from participation in the study. The severity of illness was measured using the Expanded Disability Status Scale (EDSS). ${ }^{[9]}$ The EDSS scores for $90 \%$ of our patients were fewer than 5 , and the mean score was $2.41 \pm 1.91$ when measured during the assessment of HRQoL.

A research assistant explained the confidentiality, objectives and procedures of the study to each patient before participants gave their oral consent to volunteer in the study. The study protocol complied with ethical codes issued by the Psychology and Counseling Organization of the Islamic Republic of Iran.

\section{Measurements}

All the patients in this study completed a demographic form and the Medical Outcomes Study Short-Form (SF-36). The SF-36 is a universal selfreport questionnaire used to evaluate the effect of medical treatments on quality of life (QoL). ${ }^{[10]}$ The SF-36 comprises 36 items, which measure eight subscales of HRQoL, including: (1) physical functioning; (2) role limitations due to physical health problems; (3) bodily pain; (4) general health perceptions; (5) vitality; (6) social functioning; (7) role limitations due to emotional problems; (8) general mental health. These subscales can be divided into 2 main categories: physical or mental components. The scores in every subscale and each main category ranged from 0 to 100 . Patients with the lowest scores had a worse QoL. The SF-36 was translated into Persian in 2005. ${ }^{[11]}$ The Persian version of the SF-36 possesses good psychometric properties, and it has good internal consistency (between 0.65 and 0.90) as well as adequate Cronbach's alpha reliability. The results of the comparison of the known groups, convergent validity and principal-component-factoranalysis showed that the Persian iteration of the SF36 has sufficient validity. The authors of the present study concluded that the Persian iteration of the SF-36 can be used during clinical practice and research. ${ }^{[1]}$ SPSS software version 16 (SPSS Inc, Chicago, IL) was used for the statistical analysis of the data. Descriptive statistics were used to summarize the basic features of the collected data. Group differences were assessed using MANOVA, ANOVA and an independent $t$-test. A $P \leq 0.05$ was considered statistically significant.

\section{RESULTS}

Included in this study were 80 women and 20 men with a mean age of $35.1 \pm 9.5$ years. In this study, $62 \%$ of the patients had relapsing-remitting MS, 25\% had secondary progressive MS, 9\% had primary progressive MS and 4\% had a clinically isolated syndrome. The mean duration of disease between the first diagnosis of MS and participation in the study was $6.4 \pm 3.8$ years. In this study, $80 \%$ of the patients were women, $68 \%$ of the patients were married, $30 \%$ of the patients were employed, $30 \%$ of the patients had completed primary school, $38 \%$ of the patients had completed high school and $32 \%$ of the patients had attained a university degree. The mean and standard deviation of the total SF-36 score, the physical component and the mental component were calculated for all participants. The mean scores for the full test, the physical component and the mental component were $57.53 \pm 23.27,59.48 \pm 24.63$ and $49.26 \pm 23.15$, respectively. Table 1 shows the descriptive data of the eight subscales of HRQoL in this study and a previous study conducted in Iran. ${ }^{[1]}$ The first row of Table 1 shows the mean (SD) of the current study, and the second row shows the results of the SF-36 gathered from 4,163 individuals who were randomly selected in 2005 from the general population of Tehran. ${ }^{[11]}$ To compare the current study results with the Iranian normal population results, we computed the $95 \%$ confidence interval (CI) for the mean of the scores of each of the eight subscales assessed using the Tehran 


\begin{tabular}{|c|c|c|c|c|c|c|c|c|}
\hline & $\begin{array}{c}\text { Physical } \\
\text { functioning }\end{array}$ & $\begin{array}{c}\text { Role } \\
\text { limitations } \\
\text { because } \\
\text { of physical } \\
\text { health } \\
\text { problems }\end{array}$ & $\begin{array}{l}\text { Bodily } \\
\text { pain }\end{array}$ & $\begin{array}{c}\text { General } \\
\text { health } \\
\text { perceptions }\end{array}$ & Vitality & $\begin{array}{c}\text { Social } \\
\text { functioning }\end{array}$ & $\begin{array}{c}\text { Role } \\
\text { limitations } \\
\text { because of } \\
\text { emotional } \\
\text { problems }\end{array}$ & $\begin{array}{l}\text { General } \\
\text { mental } \\
\text { health }\end{array}$ \\
\hline Current & 64.27 & 51.75 & 66.22 & 55.71 & 50.45 & 63.66 & 48.66 & 34.27 \\
\hline study & (33.45) & (42.23) & & (24.76) & & (29.74) & (43.27) & (15.44) \\
\hline $\begin{array}{l}\text { Tehran } \\
\text { normal } \\
\text { sample }^{8}\end{array}$ & $\begin{array}{c}85.3 \\
(20.8)\end{array}$ & $\begin{array}{c}70.0 \\
(38.0)\end{array}$ & $\begin{array}{c}79.4 \\
(25.1)\end{array}$ & $\begin{array}{c}67.5 \\
(20.4)\end{array}$ & $\begin{array}{c}65.8 \\
(17.3)\end{array}$ & $\begin{array}{c}76.0 \\
(24.4)\end{array}$ & $\begin{array}{c}65.6 \\
(41.4)\end{array}$ & $\begin{array}{c}67.0 \\
(18.0)\end{array}$ \\
\hline $\begin{array}{l}95 \% \mathrm{Cl} \\
\text { for Tehran } \\
\text { normal } \\
\text { sample }\end{array}$ & $66.45-67.54$ & $68.84-71.15$ & $78.63-80.1$ & $66.88-68.11$ & $65.27-66.32$ & $75.25-76.74$ & $64.34-66.85$ & $66.45-67.54$ \\
\hline
\end{tabular}

\begin{tabular}{|c|c|c|c|c|}
\hline & Single & Married & $t$ & $\mathbf{P}$ \\
\hline Full Scale & $62.31(18.90)$ & $57.50(24.46)$ & 0.90 & NS \\
\hline Physical Component & $64.13(23.48)$ & $59.48(25.18)$ & 0.81 & NS \\
\hline Mental Component & $54.21(17.26)$ & $48.60(24.74)$ & 1.06 & NS \\
\hline Physical Functioning & $71.47(33.56)$ & $64.64(32.64)$ & 0.90 & NS \\
\hline Role Limitations Because of Physical Health Problems & $59.61(44.20)$ & $51.83(41.50)$ & 0.79 & NS \\
\hline Bodily Pain & $71.44(32.07)$ & $64.22(31.16)$ & 0.99 & NS \\
\hline General Health Perceptions & $54.01(18.55)$ & $57.23(26.69)$ & 0.56 & NS \\
\hline Vitality & $55.38(15.16)$ & $49.41(26.30)$ & 1.08 & NS \\
\hline Social functioning & $71.97(23.08)$ & $62.66(31.02)$ & 1.38 & NS \\
\hline Role Limitations Because of Emotional Problems & $52.56(37.91)$ & $48.03(45.48)$ & 0.451 & NS \\
\hline General Mental Health & $36.93(11.78)$ & $34.28(16.39)$ & 0.75 & NS \\
\hline
\end{tabular}

NS: not significant

normal sample and reported these values in the third row of Table 1. The mean for each subscale score lay outside the 95\% CI; thus, the averages of the subscales in the current study are significantly lower than those of the normal group. ${ }^{[11]}$ Of note, the subscale with the lowest value in this study is the general mental health subscale.

Table 2 summarizes the scores assessing marriage status. This Table shows that the scores of unmarried patients were higher than those of married patients for every measure except for the general health perception subscale; however, the difference between the overall scores for both groups was not statistically significant. Therefore, the marital status could not significantly affect the SF-36 scores.

The mean (SD) scores of the SF-36 and its subscales for women and men are presented in Table 3 . The total average scores among men were higher than those for women except for the general health perception

\begin{tabular}{lcc}
$\begin{array}{l}\text { Table 3: Average scores for female patients and male } \\
\text { patients }\end{array}$ & Females & Males \\
\hline Full Scale & $57.14(22.16)$ & $59.08(27.87)$ \\
Physical Component & $59.17(24.05)$ & $60.71(27.47)$ \\
Mental Component & $48.49(22.0)$ & $52.35(27.70)$ \\
Physical Functioning & $63.58(33.10)$ & $67.04(35.57)$ \\
Role Limitations Because of & $51.25(42.26)$ & $53.75(43.13)$ \\
Physical Health Problems & & \\
Bodily Pain & $64.50(31.54)$ & $73.00(28.70)$ \\
General Health Perceptions & $57.36(23.59)$ & $49.07(28.67)$ \\
Vitality & $49.25(23.35)$ & $55.25(25.51)$ \\
Social Functioning & $63.65(27.93)$ & $63.68(36.95)$ \\
Role Limitations Because of & $47.08(43.63)$ & $55.00(42.26)$ \\
Emotional Problems & & \\
General Mental Health & $33.97(14.99)$ & $35.48(17.48)$ \\
\hline
\end{tabular}

subscale, which may reflect gender differences or differing expectations of health.

A 2 (gender) $\times 3$ (educational levels) factorial MANOVA was performed to examine the effect of gender and educational levels on the eight subscales of the SF-36 as dependent variables. The results from the MANOVA analyzing the eight subscales of SF36 were statistically significant (Wilkes's lambda $=$ $0.143, F(8,87)=65.047, P<.001)$. The MANOVA output for the main effect of gender (male vs. female) indicated no significant effect (Wilkes's lambda $=0.90, F(8,87)$ $=1.21$ ). No statistically significant differences among the three educational levels as the main effect were observed (Wilkes's lambda $=0.85, F(8,87)=0.895)$. The MANOVA results suggest that the interaction between gender and educational level was not statistically significant (Wilkes's lambda $=0.823, \mathrm{~F}(8,87)=1.11$ ) Therefore, a one-way repeated measures ANOVA with a Greenhouse-Geisser correction was used to detect any potential significant difference between the means of the dependent variables (the eight subscales of the SF36), which showed that the means of the eight subscales of the SF-36 scores were significantly different $[\mathrm{F}$ (4.818, $476.974)=19.114, P<0.000]$. Partial Eta Squared $\left(\eta^{2}{ }_{p}\right.$ $=0.162$ ) showed that almost $16 \%$ of the variance in the score can be accounted for by mean differences. The results from the ANOVA with repeated measures showed that there is an overall significant difference between the means of the subscales. A post-hoc Bonferroni pairwise comparison was used to detect any differences [Table 4]. Table 4 shows that there are 


\begin{tabular}{|c|c|c|c|c|c|c|c|}
\hline & $\begin{array}{l}\text { Role } \\
\text { limitations } \\
\text { of physical } \\
\text { health } \\
\text { problems }\end{array}$ & $\begin{array}{l}\text { Bodily } \\
\text { pain }\end{array}$ & $\begin{array}{l}\text { General } \\
\text { health } \\
\text { perceptions }\end{array}$ & Vitality & $\begin{array}{l}\text { Social } \\
\text { functioning }\end{array}$ & $\begin{array}{l}\text { Role } \\
\text { limitations } \\
\text { of emotional } \\
\text { problems }\end{array}$ & $\begin{array}{l}\text { General } \\
\text { mental } \\
\text { health }\end{array}$ \\
\hline $\begin{array}{l}\text { Physical functioning } \\
\text { Role limitations of } \\
\text { physical health problems } \\
\text { Bodily pain } \\
\text { General health } \\
\text { perceptions } \\
\text { Vitality } \\
\text { Social functioning } \\
\text { Role limitations of } \\
\text { emotional problems }\end{array}$ & $\begin{array}{l}D=12.52 \\
S=3.560 \\
P=.018\end{array}$ & $\begin{array}{l}\mathrm{D}=30.00 \\
\mathrm{~S}=3.05 \\
P=.000 \\
\mathrm{D}=17.47 \\
\mathrm{~S}=4.03 \\
P=.001\end{array}$ & $\begin{array}{l}\mathrm{D}=15.60 \\
\mathrm{~S}=4.41 \\
P=.017 \\
\mathrm{D}=3.08 \\
\mathrm{~S}=4.53 \\
P=\mathrm{NS} \\
\mathrm{D}=-14.39 \\
\mathrm{~S}=3.91 \\
P=.011\end{array}$ & $\begin{array}{l}\mathrm{D}=8.56 \\
\mathrm{~S}=2.98 \\
P=\mathrm{NS}{ }^{*} \\
\mathrm{D}=-3.96 \\
\mathrm{~S}=4.09 \\
P=\mathrm{NS} \\
\mathrm{D}=-21.43 \\
\mathrm{~S}=2.00 \\
P=.000 \\
\mathrm{D}=-7.04 \\
\mathrm{~S}=4.015 \\
P=\mathrm{NS}\end{array}$ & $\begin{array}{l}\mathrm{D}=-1.92 \\
\mathrm{~S}=3.71 \\
P=\mathrm{NS} \\
\mathrm{D}=-14.45 \\
\mathrm{~S}=4.06 \\
P=.016 \\
\mathrm{D}=-31.92 \\
\mathrm{~S}=3.03 \\
P=.000 \\
\mathrm{D}=-17.53 \\
\mathrm{~S}=4.02 \\
P=.001 \\
\mathrm{D}=-10.490 \\
\mathrm{~S}=3.659 \\
P=\mathrm{NS}\end{array}$ & $\begin{array}{l}\mathrm{D}=.61 \\
\mathrm{~S}=3.05 \\
P=\mathrm{NS} \\
\mathrm{D}=-11.91 \\
\mathrm{~S}=3.81 \\
P=\mathrm{NS} \\
\mathrm{D}=-29.38 \\
\mathrm{~S}=2.32 \\
P=.000 \\
\mathrm{D}=-14.99 \\
\mathrm{~S}=3.87 \\
P=.005 \\
\mathrm{D}=-7.953 \\
\mathrm{~S}=2.691 \\
P=\mathrm{NS} \\
\mathrm{D}=2.53 \\
\mathrm{~S}=3.42 \\
P=\mathrm{NS}\end{array}$ & $\begin{array}{l}\mathrm{D}=13.82 \\
\mathrm{~S}=2.74 \\
P=.000 \\
\mathrm{D}=1.30 \\
\mathrm{~S}=3.79 \\
P=\mathrm{NS} \\
\mathrm{D}=-16.17 \\
\mathrm{~S}=1.66 \\
P=.000 \\
\mathrm{D}=-1.78 \\
\mathrm{~S}=3.71 \\
P=\mathrm{NS} \\
\mathrm{D}=5.260 \\
\mathrm{~S}=2.037 \\
P=\mathrm{NS} \\
\mathrm{D}=15.75 \\
\mathrm{~S}=3.08 \\
P=.000 \\
\mathrm{D}=13.212 \\
\mathrm{~S}=2.092 \\
P=.000\end{array}$ \\
\hline
\end{tabular}

*Not significant

several significant differences between the means.

For example, physical and social functions were not statistically different; however, physical function was statistically different from the general health perceptions and general mental health. The paired $t$-test indicated that there was a significant difference between the average of the physical component and that of the mental component $(t=5.72$, df $=99, P<.001)$.

\section{DISCUSSION}

In this study, our findings suggest that the total HRQoL scores in patients with MS were significantly lower than those of the normal general population in Iran. ${ }^{[1]}$ Similar findings have been previously reported in other countries, ${ }^{[12,13]}$ which also demonstrated lower HRQoL scores in patients with MS when compared with those of healthy persons. Furthermore, HRQoL scores among patients with MS were even lower than those among patients with other chronic diseases such as rheumatoid arthritis and inflammatory bowel disease. ${ }^{[14]}$ Reports from other countries have shown the same results, for example, patients with MS have more frequently reported chronic pain than members of a healthy control group. ${ }^{[15]}$ Alternatively, these reports have documented a higher percent of unemployment and retirement among patients with MS. ${ }^{[16]}$ The authors of a review article in Croatia described patients with MS as having a lower quality of life than that of either a non-patient population or an otherwise unhealthy population. ${ }^{[17]}$ The above mentioned findings can be explained by the chronic and long-standing course of MS as well as the unpredictable and disabling nature of the disease.
Our study also shows that the scores of the mental components of the HRQoL were significantly lower than those of the physical components among the study participants. Of note, it is commonly believed that MS is a progressive and physically disabling sickness, and patients with MS are more likely to display mental and psychological problems. Patients with MS may feel low self-efficacy because they feel that there are many limitations affecting their activities, and they are restricted from participating in social events. Low self-efficacy in a chain of events that can impact work, social life, family relationships, mood and QoL. ${ }^{[18]}$ Common neuropsychiatric disorders experienced by patients with MS are anxiety, depression, cognitive decline, irritability and anger. $^{[19]}$ Some studies have reported that the rate of depression, anxiety and suicide in the patients with MS is higher than that of the general population with other medical conditions. ${ }^{[20]}$ The neuropsychiatric symptoms of MS occur early during the course of the disease. For example, researchers observe the presence of cognitive function impairment in 60\% of patients with a disease duration of less than 2 years. ${ }^{[21]}$ Additionally, research suggests that as early as one year following diagnosis with MS, about half of patients exhibit depression, anxiety and distress. ${ }^{[22]}$ In a recent critical review conducted by Ciro et al. ${ }^{[23]}$ the authors found several case reports of bipolar disorder clearly preceding MS onset. Some studies examining the HRQoL in the patients with MS have shown that the clinicians are more concerned with the physical problems of the disease whereas the patients mainly believed that their vitality, role limitations, emotional problems, and mental health are essential indicators of disease burden. ${ }^{[24]}$ 
Consistent with our findings, other studies have shown that there was no significant difference between men and women with respect to HRQoL; ${ }^{[13,25]}$ however, some studies have reported that women with MS had lower HRQoL scores than men. ${ }^{[26]}$ Casetta et al. ${ }^{[27]}$ have studied 370 patients with MS to evaluate gender differences with respect to HRQoL and have reported that the impact of disability is significantly more in men, especially when measured using HRQoL scales that are related to mental well-being.

Our findings show that when compared with married patients, unmarried patients with MS attained better (but not statistically significant) scores in the majority of QoL domains. This finding lies in contrast to results of other studies which have shown that QoL scores are lower in unmarried patients. ${ }^{[28]}$ Whereas the support provided by family members alleviates some physical and mental problems in patients with chronic diseases such as MS, increasing disability and sexual dysfunction in patients who have no supporting family can result in lower HRQoL. Although in our study there was no relationship between age and HRQoL among patients with MS, other studies have reported varied results regarding this issue. Some researchers have reported lower HRQoL scores among older patients; ${ }^{[29]}$ However, other researchers have documented better HRQoL scores among older patients. ${ }^{[30]}$ Lower HRQoL scores among the elderly, healthy coping mechanisms and better adjustment to the disease seem to be responsible for the varied effects of age on HRQoL. ${ }^{[29]}$

Finally, the findings of the present study show that educational level has no impact on HRQoL. ŠabanagićHajrić and Alajbegović ${ }^{[5]}$ have reported that educated patients had higher HRQoL than uneducated or lesseducated patients; however, Busche et al. ${ }^{[31]}$ have shown that high school and college graduates with MS had higher scores in the physical components of the HRQoL. Furthermore, Patti et al. ${ }^{[32]}$ have documented that educational level has been an independent predictor of both physical and mental domains of HRQoL.

In conclusion, HRQoL in patients with MS is significantly lower than that of the normal population especially with respect to the mental domain. In the future, should physicians pay closer attention to the cognitive and other neuropsychiatric components of HRQoL as well as the physical components of HRQoL in patients with MS, they could better improve the appropriate management of this disease.

\section{Acknowledgments}

The authors would like to thank Ms. Mehrnaz Gholami of the Shiraz Neuroscience Research Center for editing the language of the manuscript and Ms. Hosseini for her help.

Financial support and sponsorship

Nil.

\section{Conflicts of interest}

There are no conflicts of interest.

\section{REFERENCES}

1. Compston A, Coles A. Multiple sclerosis. Lancet 2008;372:1502-17.

2. Multiple Sclerosis International Federation: Atlas of MS 2013. London, England, 2013.

3. Taillefer MC, Dupuis G, Roberge MA, LeMay S. Health-related quality of life models: systematic review of the literature. Soc Indic Res 2003;64:293-323.

4. Da Rocha NS, Schuch FB, Fleck MP. Gender differences in perception of quality of life in adults with and without chronic health conditions: the role of depressive symptoms. $J$ Health Psychol 2014;19:721-9.

5. Šabanagić-Hajrić S, Alajbegović A. Impacts of education level and employment status on health-related quality of life in multiple sclerosis patients. Med Glas (Zenica) 2015;12:61-7.

6. Lessan-Pezeshki M, Rostami Z. Contributing factors in health-related quality of life assessment of ESRD patients: a single center study. Int J Nephrol Urol 2009;1:129-36.

7. Prazeres F, Figueiredo D. Measuring quality of life of old type 2 diabetic patients in primary care in Portugal: a cross-sectional study. J Diabetes Metab Disord 2014;13:68.

8. Polman CH, Reingold SC, Banwell B, Clanet M, Cohen JA, Filippi M, Fujihara K, Havrdova E, Hutchinson M, Kappos L, Lublin FD, Montalban X, O'Connor P, Sandberg-Wollheim M, Thompson AJ, Waubant E, Weinshenker B, Wolinsky JS. Diagnostic criteria for multiple sclerosis: 2010 revisions to the McDonald criteria. Ann Neurol 2011;69:292-302.

9. Kurtzke JF. Rating neurologic impairment in multiple sclerosis: an expanded disability status scale (EDSS). Neurology 1983;33:1444-52.

10. Ware JE Jr, Sherbourne CD. The MOS 36-item short-form health survey (SF-36). I. Conceptual framework and item selection. Med Care 1992;30:473-83.

11. Montazeri A, Goshtasebi A, Vahdaninia M, Gandek B. The Short Form Health Survey (SF-36): translation and validation study of the Iranian version. Qual Life Res 2005;14:875-82.

12. Mitchell AJ, Benito-León J, González JM, Rivera-Navarro J. Quality of life and its assessment in multiple sclerosis: Integrating physical and psychological components of well-being. Lancet Neurol 2005;4:556-66.

13. Benedict RH, Wahlig E, Bakshi R, Fishman I, Munschauer F, Zivadinov R, Weinstock-Guttman B. Predicting quality of life in multiple sclerosis: accounting for physical disability, fatigue, cognition, mood disorder, personality, and behavior change. $J$ Neurol Sci 2005;231:29-34.

14. Rudick RA, Miller D, Clough JD, Gragg LA, Farmer RG. Quality of life in multiple sclerosis. Comparison with inflammatory bowel disease and rheumatoid arthritis. Arch Neurol 1992;49:1237-42.

15. Olmo NRS, de Melo STL, de Brito LA, Fragoso YD. Patients with multiple sclerosis present more chronic and recurrent pain than a control population. Austin $J$ Mult Scler Neuroimmunol 2015;2:1005.

16. Fragoso, YD, Finkelsztejn A, Giacomo MCB, Russo L, Cruz WS. The effect of multiple sclerosis on the professional life of a group of Brazilian patients. Arq Neuropsiquiatr 2010;68:914-17.

17. Kes VB, Cengic L, Cesarik M, Tomas AJ, Zavoreo I, Matovina LZ, Coric L, Drnasin S, Demarin V. Quality of life in patients with multiple sclerosis. Acta Clin Croat 2013;52:107-11.

18. Fjeldstad C, Pardo G. Self-efficacy, physical activity and QOL in people with MS. J Neurol Neurophysiol 2014;5:1-5.

19. Feinstein A. The neuropsychiatry of multiple sclerosis. Can $J$ Psychiatry 2004;49:157-63.

20. Halper J. The psychosocial effect of multiple sclerosis: the impact of relapses. J Neurol Sci 2007;256:S34-8.

21. Brassington JC, Marsh NV. Neuropsychological aspects of multiple 
sclerosis. Neuropsychol Rev 1998; 8: 43-77.

22. Janssens AC, Van Doorn PA, De Boer JB, Van der Meché FG, Passchier J, Hintzen RQ. Impact of recently diagnosed multiple sclerosis on quality of life, anxiety, depression and distress of patients and partners. Acta Neurol Scand 2003;108:389-95.

23. Marangoni C, Nanni MG, Grassi L, Faedda GL. Bipolar disorder preceding the onset of multiple sclerosis. Neuroimmunol Neuroinflamm 2015;2:195-9.

24. Rothwell PM, McDowel Z, Wong CK, Dorman PJ. Doctors and patients don't agree: cross sectional study of patients' and doctors' perceptions and assessments of disability in multiple sclerosis. BMJ 1997;314:1580-3

25. Ford HL, Gerry E, Johnson MH, Tennant A. Health status and quality of life of people with multiple sclerosis. Disabil Rehabil 2001;23:516-21.

26. Hopman WM, Harrison MB, Coo H, Friedberg E, Buchanan M, VanDenKerkhof EG. Associations between chronic disease, age and physical and mental health status. Chronic Dis Can 2009;29:108-16.

27. Casetta I, Riise T, Wamme Nortvedt M, Economou NT, De Gennaro R, Fazio P, Cesnik E, Govoni V, Granieri E. Gender differences in healthrelated quality of life in multiple sclerosis. Mult Scler 2009;15:1339-46.
28. Baumstarck-Barrau K, Simeoni MC, Reuter F, Klemina I, Aghababian V, Pelletier J, Auquier P. Cognitive function and quality of life in multiple sclerosis patients: a cross-sectional study. BMC Neurol 2011;11:17.

29. Isaksson AK, Ahlström G, Gunnarsson LG. Quality of life and impairment in patients with multiple sclerosis. $J$ Neurol Neurosurg Psychiatry 2005;76:64-9.

30. Simeoni M, Auquier P, Fernandez O, Flachenecker P, Stecchi S, Constantinescu C, Idiman E, Boyko A, Beiske A, Vollmer T, Triantafyllou N, O'Connor P, Barak Y, Biermann L, Cristiano E, Atweh S, Patrick D, Robitail S, Ammoury N, Beresniak A, Pelletier J; MusiQol study group. Validation of the multiple sclerosis international quality of life questionnaire. Mult Scler 2008;14:219-30.

31. Busche KD, Fisk JD, Murray TJ, Metz LM. Short term predictors of unemployment in multiple sclerosis patients. Can $J$ Neurol Sci 2003;30:137-42.

32. Patti F, Pozzilli C, Montanari E, Pappalardo A, Piazza L, Levi A, Onesti E, Pesci I; Italian Study Group On Quality Of Life In Ms. Effects of education level and employment status on HRQoL in early relapsing-remitting multiple sclerosis. Mult Scler 2007;13:783-91. 